\title{
The moderating effects of mindful eating on the relationship between emotional functioning and eating styles in overweight and obese women
}

\author{
Kamila Czepczor-Bernat ${ }^{1}$ - Anna Brytek-Matera ${ }^{1}$ [D $\cdot$ Carla Gramaglia $^{2,3} \cdot$ Patrizia Zeppegno $^{2,3}$
}

Received: 30 January 2019 / Accepted: 22 June 2019 / Published online: 16 July 2019

(c) The Author(s) 2019

\begin{abstract}
Purpose The aim of the current study was to examine the moderating effect of mindful eating on the relationship between emotional functioning and eating styles in overweight and obese women.

Methods One hundred and eighty four overweight and obese adult women (BMI $30.12 \pm 3.77 \mathrm{~kg} / \mathrm{m}^{2}$ ) were assessed with the Difficulties in Emotion Regulation Scale, the Positive and Negative Affect Schedule, the Three Factor Eating Questionnaire and the Mindful Eating Scale.

Results Mindful eating significantly moderated several of the relationships between emotional functioning and eating styles. At all levels of mindful eating, emotion dysregulation and negative affect are both associated with greater emotional eating, but with stronger associations for high levels of mindful eating. For people low in mindful eating, both emotion dysregulation and negative affect are associated with lower restrictive eating, and neither of them are associated with uncontrolled eating. For people high in mindful eating, neither emotion dysregulation nor negative affect are associated with restrictive eating, and only negative affect is associated with greater uncontrolled eating.

Conclusion When mindful eating techniques are included as part of an intervention for overweight or obese individuals, it is even more important that those interventions should also include techniques to reduce emotion dysregulation and negative affect.
\end{abstract}

Level of evidence Level V, descriptive study.

Keywords Overweight $\cdot$ Obesity $\cdot$ Mindful eating $\cdot$ Emotional dysregulation $\cdot$ Negative emotions $\cdot$ Eating styles

This article is part of topical collection on Obesity Paradox.

Kamila Czepczor-Bernat and Anna Brytek-Matera contributed equally.

Anna Brytek-Matera

abrytek-matera@swps.edu.pl

1 Katowice Faculty of Psychology, SWPS University of Social Sciences and Humanities, Technikow 9, 40-326 Katowice, Poland

2 Dipartimento di Medicina Traslazionale, Psychiatry Institute, Università degli Studi del Piemonte Orientale, Via Solaroli 17, 28100 Novara, Italy

3 Psychiatry Institute, Maggiore della Carità Hospital, C.so Mazzini 18, 28100 Novara, Italy

\section{Introduction}

According to epidemiological data, overweight and obesityrelated problems are increasing worldwide, also because of the poor effectiveness of long-term treatment methods, with relevant consequences for the population's health and healthcare costs [1-4]. New explanatory models for the onset and maintenance of overweight and obesity have been assessed in the recent literature [5-10], underscoring the role of high levels of emotional dysregulation, high levels of negative emotions [11, 12] and low levels of mindful eating [13]. While it is widely acknowledged that eating styles in overweight and obese individuals are more maladaptive than those of normal body weight ones [14-16], and include behaviours such as overeating, emotional eating, uncontrolled eating, it is still necessary to better clarify the relation among these variables. 
Abnormal emotional functioning may involve difficulty in correctly identifying, interpreting, and coping with emotions [17-19] and a chronic experience of high levels of negative emotions [18]. Emotional dysregulation entails a poor ability to use emotions as an important source of information $[17,19,20]$, and the consequent use of maladaptive coping patterns with negative emotions and stress [18], which may include regulation of emotional states by food intake (for instance: eating, overeating or restricting eating in response to emotions) [9, 21-23].

Emotional, uncontrolled and restrictive eating are problematic eating behaviours [24, 25], respectively, characterized by food intake independent of hunger and satiety feelings, but rather based on emotional stimuli [26-28]; overeating accompanied by a sense of lack of control [11, 29]; adoption of food restrictions aimed to control and manage body weight [30]. Overall, problematic eating behaviours lead to the loss of natural and intuitive eating and difficulties in discriminating various emotions from a state of hunger or satiety [24, 27, 31], which can be treated and restored with the aid of mindfulness techniques [26, 32-35].

The concept of mindful eating $[25,36]$ refers to eating in a conscious way, with the aim of satisfying body physical needs and their associated pleasure, focusing on bodily sensations associated with food intake (intuitive eating), rather than "being on automatic pilot" and using food intake to regulate emotions [25, 36, 37].

Previous reports about non-clinical samples describe that a mindfulness state is negatively associated with unhealthy eating styles (e.g., emotional and uncontrolled eating) [38-40], while it is positively related to healthy eating behaviours [41, 42]. Moreover, evidence suggests that deficits in emotion dysregulation $[9,23,43]$ and a high level of negative emotions $[8,22]$ play a relevant role in the development and maintenance of obesity. Because of their impact on emotional regulation, emotional self-awareness, and adaptive coping with affect, interventions using mindfulness and mindful eating techniques proved to be effective in reducing binge eating episodes, depressive symptoms and emotional eating, as well as in enhancing intuitive eating [21, 25, 26, $44,45]$. The effectiveness of mindful eating interventions in obese patients has been supported as well [31, 35, 46]. Meta-analyses of mindfulness interventions offered to obese patients have supported their effectiveness on weight loss and decreasing maladaptive eating behaviours [47-52], albeit with different effect sizes for BMI (e.g., small [51], moderate [47]). Furthermore, a longer distance between pretest and follow-up was associated with greater weight loss [52]. Katterman et al. [49] highlight that the long-term studies of mindful eating interventions should be done to assess effectiveness of mindfulness interventions in reducing BMI.

There are still gaps in understanding the relation among emotional functioning and dysregulation, eating styles and mindful eating in overweight and obese women. In addition, to our knowledge, no study has been conducted to assess mindful eating as a moderator between emotional functioning and eating styles.

Therefore, the aim of our study was to: (1) assess whether the relationship between emotional dysregulation and eating styles (emotional eating, uncontrolled eating, restrictive eating) was moderated by mindful eating, (2) evaluate whether the relationship between negative emotions and eating styles (emotional eating, uncontrolled eating and restrictive eating) was moderated by mindful eating.

Mindful eating was expected to moderate the relationship between emotion dysregulation/negative emotions and eating styles (emotional eating, restrictive eating and uncontrolled eating); in other words, high or medium mindfulness would mean a non-significant relationship between dysregulation/negative emotions and eating style.

\section{Materials and methods}

\section{Participants}

Three hundred patients were recruited from September 2017 to January 2018 through flyer advertisement at the Center for Eating Disorders in Grand Poland, and at the Psychodietetics and Eating Disorders Treatment Center in Katowice, which are both institutions dedicated to the treatment of overweight/obese and eating disorder patients. The flyers were distributed by staff and included contact information of the researcher.

Patients were screened according to inclusion and exclusion criteria to ensure the best possible homogeneity of the study sample. Inclusion criteria were the following: body mass index $(\mathrm{BMI}) \geq 25 \mathrm{~kg} / \mathrm{m}^{2}$; female gender. Patients were excluded if they were unwilling to take part in the study, and in case of current axis I disorder comorbidity [53]. Exclusion criteria such as gender and axis I comorbidity were adopted in the present study according to previous research which showed that women show higher levels of abnormal eating behaviours than men [e.g., 54] and that patients (BMI $\geq 25 \mathrm{~kg} / \mathrm{m}^{2}$ ) with axis I comorbidity function worse than those without mental issues [e.g., eating disorders; 55].

A total of 151 women met the eligibility criteria and participated in the study. Patients were supplied no fee or reimbursement for their participation. Demographic and clinical characteristics are reported in Table 1.

\section{Measures}

Patients' weight and height were measured and body mass index (BMI) was calculated. 
Table 1 Descriptive features of the sample

\begin{tabular}{|c|c|c|c|}
\hline & $M(\mathrm{SD})$ & Min & $\operatorname{Max}$ \\
\hline \multicolumn{4}{|c|}{ Demographic and clinical characteristics } \\
\hline Body mass index $\left(\mathrm{kg} / \mathrm{m}^{2}\right)$ & $30.12(3.77)$ & 25.22 & 51.20 \\
\hline \multirow[t]{2}{*}{ Age (years) } & $35.73(20.40)$ & 18 & 64 \\
\hline & & & $N(\%)$ \\
\hline \multicolumn{4}{|l|}{ Category of BMI } \\
\hline \multicolumn{2}{|l|}{ Overweight } & & $83(54.97)$ \\
\hline \multicolumn{2}{|l|}{ Obesity } & & $68(45.03)$ \\
\hline \multicolumn{4}{|l|}{ Clinical characteristics } \\
\hline \multicolumn{4}{|l|}{ Every day weighing } \\
\hline \multicolumn{2}{|l|}{ Yes } & & $16(10.60)$ \\
\hline \multicolumn{2}{|l|}{ No } & & $135(89.40)$ \\
\hline \multicolumn{4}{|l|}{ Action for weight loss } \\
\hline \multicolumn{2}{|l|}{ Yes } & & $55(36.42)$ \\
\hline \multicolumn{2}{|l|}{ No } & & $96(63.58)$ \\
\hline \multicolumn{4}{|l|}{ Methods of weight loss } \\
\hline \multicolumn{2}{|l|}{ Dieting } & & $29(19.21)$ \\
\hline \multicolumn{2}{|l|}{ Physical activity } & & $23(15.23)$ \\
\hline \multicolumn{2}{|l|}{ Use of laxatives } & & $0(0)$ \\
\hline \multicolumn{2}{|l|}{ Vomiting } & & $1(.66)$ \\
\hline \multicolumn{2}{|l|}{ Starvation } & & $2(1.32)$ \\
\hline \multicolumn{4}{|l|}{ Number of meals a day } \\
\hline \multicolumn{2}{|l|}{1} & & $0(0)$ \\
\hline \multicolumn{2}{|l|}{2} & & $9(5.96)$ \\
\hline \multicolumn{2}{|l|}{3} & & $35(23.18)$ \\
\hline \multicolumn{2}{|l|}{4} & & $71(47.02)$ \\
\hline \multicolumn{2}{|l|}{5} & & $32(21.20)$ \\
\hline \multicolumn{2}{|l|}{6 and more } & & $4(2.64)$ \\
\hline \multicolumn{4}{|l|}{ Snacking in between meals } \\
\hline \multicolumn{2}{|l|}{ Always } & & $14(9.27)$ \\
\hline \multicolumn{2}{|l|}{ Often } & & $43(28.48)$ \\
\hline Sometimes & & & $67(44.37)$ \\
\hline Rarely & & & $25(16.56)$ \\
\hline Never & & & $2(1.32)$ \\
\hline Products snacking in betwe & hoice) & & \\
\hline Fruits & & & $44(29.14)$ \\
\hline Vegetables & & & $5(3.31)$ \\
\hline Sweets & & & $67(44.37)$ \\
\hline Other & & & $33(21.85)$ \\
\hline
\end{tabular}

Assessment included the following questionnaires: the Difficulties in Emotion Regulation Scale [17], the Positive and Negative Affect Schedule [56], the Three Factor Eating Questionnaire [57] and the Mindful Eating Scale [58].

\section{The Difficulties in Emotion Regulation Scale}

It measures the overall level of emotional dysregulation. It consists of 36 items, grouped in 6 subscales: non-acceptance of emotional responses, difficulty in engaging in a goaldirected behaviour, impulse control difficulties, lack of emotional awareness, limited access to emotion regulation strategies and lack of emotional clarity [17, 59]. Each item is rated on a 5-point Likert scale (from 1- "almost never" to 5-“almost always"): lower scores indicate higher adaptive emotion regulation.

The standard forward-backward translation procedure was used to create the Polish version of the questionnaire. 
In the present study, Cronbach's alpha reliability coefficient for total scores was 0.95 .

\section{The Positive and Negative Affect Schedule}

It is a 20-item self-report measure of "negative" and "positive" emotions [56, 60]. Each item is rated on a 5-point Likert scale (from 1-“slightly or not at all" to 5-"very strongly"). The higher the score is, the higher the negative (NA; e.g., afraid, worried) and positive (PA; e.g., active, zestful) emotions will be.

The Polish version of the questionnaire was used [61]. In the present study, Cronbach's alpha reliability coefficient was 0.94 both for the negative and the positive dimensions. In this study, only the negative affect subscale was used.

\section{The Three Factor Eating Questionnaire (TFEQ-R18) [57]}

This is an 18-item scale used to assess eating styles, and contains three subscales: emotional, uncontrolled, and restrictive eating. Items $1-17$ item are rated on a 4-point Likert scale (1-13: from 1-“definitely false" to 4-"definitely true"; 14: from 1-“only at meal times" to 4- "almost always"; 15: from 1-“almost never" to 4-"almost always"; 16: from 1-“unlikely" to 4-"very likely"; 17: from 1-“never" to 4-"at least once a week"), while item 18 is rated on an 8-point Likert scale (from 1-"eating whatever you want, whenever you want it" to 8- "constantly limiting food intake and never giving in"; responses 1 and 2 were recoded into 1; 3 and 4 into 2; 5 and 6 into 3; and 7 and 8 into 4 [15]. The higher the score is, the more maladaptive the eating styles are.

The Polish version of the questionnaire was used [15]. In the present study, Cronbach's alpha reliability coefficient for the above-mentioned subscales was $0.88,0.88$ and 0.77 .

\section{The Mindful Eating Scale}

The Mindful Eating Scale [58] measures overall mindfulness in the domain of eating behaviours. It includes 28 items and 6 subscales: acceptance, awareness, non-reactivity, routine, distractibility, unstructured [58]. Each item is rated on a 4-point Likert scale (from 1-“never" to 4-“usually"); higher scores indicate more mindful eating.

The standard forward-backward translation procedure was used to create the Polish version of the questionnaire. In the present study, Cronbach's alpha reliability coefficient for total scores was 0.88 .

\section{Statistical analysis}

Statistical analysis was performed with the Statistical Package for Social Sciences (version 22.0). Univariate and multivariate logistic regressions were used to investigate predictors of mindful eating. MACRO "PROCESS" [62] with bootstrap $N=10,000$ was used to analyse the moderating effects. Moderation, unlike mediation, gives the possibility to determine the level at which the relation between the variable $X$ and $Y$ depends on the level of the third variable $(M)$. According to Hayes [62] "when the goal is to uncover the boundary conditions of an association between two variables, moderation analysis is used. An association between two variables $X$ and $Y$ is said to be moderated when its size or sign depends on a third variable or set of variables".

All tables were created according to Hayes guidelines [62]. These tables are based on the statistical model of Hayes moderation [62].

\section{Results}

\section{Descriptive statistics for variables}

To summarize the obtained data, descriptive statistics (mean, standard deviation, minimum and maximum) for mindful eating, emotional dysregulation, negative affect and eating styles are reported in Table 2.

\section{Moderation analysis}

Regarding the relationship between emotional dysregulation and eating styles, mindful eating was a significant moderator for emotional eating, $R=0.53, F(3,147)=18.63$, $p=0.0001, \mathrm{MSE}=6.72, R^{2}$-chng $=0.03$, and restrictive eating, $R=0.41, F(3,147)=9.06, p=0.04, \mathrm{MSE}=20.92, R^{2}$ chng $=0.02$, but not for uncontrolled eating, $R=0.69, F(3$, $147)=43.99, p=0.0001, \mathrm{MSE}=23.69, R^{2}-\mathrm{chng}=0.001(\mathrm{see}$ Tables 3, 4).

Further analysis showed a significant moderation effect of mindful eating for the relationship between negative emotions and emotional eating, $R=0.55, F(3,147)=21.22$, $p=0.0001$, MSE $=6.47, R^{2}$-chng $=0.05$, restrictive eating, $R=0.33, F(3,147)=5.86, p=0.001, \mathrm{MSE}=22.34$, $R^{2}$-chng $=0.03$ and uncontrolled eating, $R=0.71, F(3$,

Table 2 Descriptive statistic for variables

\begin{tabular}{lrrrc}
\hline Variable & \multicolumn{1}{c}{$M$} & \multicolumn{1}{c}{ SD } & Minimum & Maximum \\
\hline Mindful eating & 72.45 & 11.14 & 47.00 & 98.00 \\
Emotional dysregulation & 94.97 & 27.18 & 48.00 & 159.00 \\
Negative affect & 21.31 & 9.08 & 10.00 & 46.00 \\
Eating styles & & & & \\
Emotional eating & 8.43 & 3.01 & 3.00 & 12.00 \\
Restrictive eating & 17.76 & 4.95 & 7.00 & 28.00 \\
Uncontrolled eating & 21.58 & 6.64 & 10.00 & 36.00 \\
\hline
\end{tabular}


Table 3 Regression analysis testing moderating effect of mindful eating
Table 4 Relationships with disordered eating styles at different levels of mindful eating

\begin{tabular}{|c|c|c|c|c|c|c|}
\hline & \multicolumn{2}{|c|}{ Emotional eating } & \multicolumn{2}{|c|}{ Restrictive eating } & \multicolumn{2}{|c|}{ Uncontrolled eating } \\
\hline & $b$ & $t$ & $b$ & $t$ & $b$ & $t$ \\
\hline Mindful eating (ME) & -0.19 & $-2.75^{* *}$ & -0.45 & $-3.62 * * *$ & -0.35 & $-2.63^{* *}$ \\
\hline Emotion dysregulation (ED) & -0.07 & -1.48 & -0.23 & $-2.73 * *$ & 0.04 & 0.46 \\
\hline Negative affect (NE) & -0.31 & $-2.39 * *$ & -0.59 & $-2.41 *$ & -0.46 & -1.89 \\
\hline $\mathrm{ME} \times \mathrm{ED}$ & 0.002 & $2.49 *$ & 0.001 & $1.93 *$ & -0.0001 & -0.34 \\
\hline $\mathrm{ME} \times \mathrm{NA}$ & 0.01 & $3.30 * *$ & 0.01 & $2.10^{*}$ & 0.01 & $2.33 * *$ \\
\hline
\end{tabular}

$b$ - unstandardized coefficients

$* p<0.05, * * p<0.01, * * * p<0.001$

\begin{tabular}{|c|c|c|c|c|c|c|}
\hline \multirow[t]{2}{*}{ Level of mindful eating } & \multicolumn{2}{|c|}{ Emotional eating } & \multicolumn{2}{|c|}{ Restrictive eating } & \multicolumn{2}{|c|}{$\begin{array}{l}\text { Uncontrolled } \\
\text { eating }\end{array}$} \\
\hline & $b$ & $t$ & $b$ & $t$ & $b$ & $t$ \\
\hline \multicolumn{7}{|c|}{ Relationships with emotion dysregulation } \\
\hline Low (below $1 \mathrm{SD}$ ) & 0.03 & $3.06 * *$ & -0.09 & $-4.26 * * *$ & 0.01 & 0.66 \\
\hline Medium $(M)$ & 0.05 & $4.87 * * *$ & -0.06 & $-3.03 * *$ & 0.01 & 0.44 \\
\hline High (above $1 \mathrm{SD}$ ) & 0.07 & $4.77 * * *$ & -0.03 & -1.22 & 0.00 & 0.15 \\
\hline \multicolumn{7}{|c|}{ Relationships with negative affect } \\
\hline Low (below $1 \mathrm{SD}$ ) & 0.07 & $2.68 * *$ & -0.13 & $-2.57 *$ & 0.05 & 0.91 \\
\hline Medium $(M)$ & 0.14 & $5.41 * * *$ & -0.05 & -0.97 & 0.14 & $2.81 *$ \\
\hline High (above $1 \mathrm{SD}$ ) & 0.21 & $5.40 * * *$ & 0.04 & 0.48 & 0.23 & $3.14 * *$ \\
\hline
\end{tabular}

$b$ - unstandardized coefficient, $1 \mathrm{SD}$ - low score (61.32), $M$-medium score $(72.45),+1 \mathrm{SD}$-high score (83.58)

$* p<0.05, * * p<0.01, * * * p<0.001$
147) $=49.96, p=0.0001, \mathrm{MSE}=22.26, R^{2}$-chng $=0.02($ see Tables 3, 4).

Greater restrictive eating was associated with lower levels of both emotional dysregulation and negative affect, but only at lower levels of mindful eating. For participants high in mindful eating, neither emotional dysregulation nor negative affect predicted restrictive eating. Regarding emotional eating, greater scores were positively associated with greater degrees of both emotion dysregulation and negative affect for all levels of mindful eating, although these relationships were most pronounced for medium and high levels of mindful eating. Regarding uncontrolled eating, greater scores were positively associated with greater degrees of negative affect, but only for medium and high levels of mindful eating.

\section{Discussion}

Mindful eating significantly moderated several of the relationships between emotional functioning and eating styles. At all levels of mindful eating, emotion dysregulation and negative affect are both associated with greater emotional eating, but with stronger associations for high levels of mindful eating. For people low in mindful eating, both emotion dysregulation and negative affect are associated with lower restrictive eating, and neither of them are associated with uncontrolled eating. For people high in mindful eating, neither emotion dysregulation nor negative affect are associated with restrictive eating, and only negative affect is associated with greater uncontrolled eating. Regarding clinical implications, the treatment of overweight and obese patients should focus on an increase in mindful eating while dealing with emotional functioning and restrictive eating. The effectiveness of mindful eating techniques for the treatment of bariatric surgery and non-bariatric obese patients has been supported [35, 63-66], while little is known about the importance of this approach in overweight individuals. Training in mindful eating (which reduces restrictive eating) strengthens a non-judgmental eating attitude and enhances the ability to properly address nutritional needs (which is associated with food intake based on body wisdom and natural physiological signals of hunger satiety) [13, 25, 36, 63]. This is an interesting and novel finding, as research on mindful eating typically describes this kind of intervention as helpful in reducing binge eating, overeating and emotional eating but not in restrictive eating. 
However, our findings are not consistent with the literature about this topic [64], showing that (non-clinical) individuals with restrictive eating are characterized by high levels of emotional dysregulation. That research hypothesizes that restrictive eating is the most commonly used coping strategy for non-clinical individuals with poor emotion regulation who lack adaptive coping skills [64]. However, our findings would mean that the relationship between emotional functioning and restrictive eating are different among overweight and obese women (compared to a non-clinical sample), because in our sample, greater emotion dysregulation and higher negative affect are associated with lower restrictive eating. The possible reasoning for such opposite findings can be related to the Hemmingsson theory [6]. This author (based on previous research) assumes that people who in the future will be obese, from childhood are characterized by abnormal emotional functioning with which they try to cope by eating. Observing the trajectories of developing abnormal eating behaviours in this group, food intake became more and more non-restrictive and uncontrolled and these processes resulted in weight gain. Ultimately, these individuals lose emotional, cognitive and behavioural control over food intake and cannot introduce the dietary restrictions for weight reduction [6].

The analyses regarding the moderation effect of mindful eating in the relationship between emotional or uncontrolled eating and emotional dysregulation did not yield any suggestion about possible clinical implications. Similarly, this is presented in relation to negative emotions because of difficulties in interpretation of results. Although the model referring to emotional eating is significant, it is not possible to specify the level of mindful eating that is recommended to achieve with patients (at each level of mindful eating, the relation between emotional regulation or negative emotions and emotional eating is significant). Likewise, the same models for uncontrolled eating were difficult to interpret. The first model was not significant and the second one was unintelligible, because (a) negative emotions were not linked (directly and significantly) to uncontrolled eating and (b) a low level of mindful eating in the relationship between negative emotions and uncontrolled eating is insignificant.

Taking into consideration the low levels of mindful eating, both emotion dysregulation and negative affect are associated with less unhealthy restrictive eating. Likewise, mindful eating seems to be harmful with respect to the other two forms of unhealthy eating styles, such that at high levels of mindful eating, both emotion dysregulation and negative affect were associated with even greater degrees of both emotional eating and uncontrolled eating.

These results would suggest a paradoxical indication for a therapy to reduce the mindfulness level, nevertheless this indication is not coherent with mindful eating practice protocols [25, 34, 67-69], because they assume that a high level of mindful eating should not only lead to a reduction in restrictive eating (associated with avoiding "forbidden food") but also a decrease in emotional and uncontrolled eating $[13,25]$. The BASICS technique achieves a reduction in the emotional eating level through mini-meditations connected with mindful meal and body scanning for uncontrolled eating $(\mathrm{B}$ - breathe and belly check for hunger and satiety before you eat; A-assess your food; $\mathrm{S}$ - slow down; $\mathrm{I}$-investigate your hunger throughout the meal, particularly halfway through; $\mathrm{C}$ - chew your food thoroughly; $\mathrm{S}$ - savour your food [13, pp. 46-67]). Perhaps, there are some variables that can moderate the effect of mindful eating on emotional eating and uncontrolled eating. Therefore, other explanations for non-specific or insignificant relationships described above should be sought. Perhaps, the role of mindful eating in the relationship between emotional functioning and emotional and uncontrolled eating is particularly relevant in bariatric surgery candidates [31, 35, 70]. Moreover, Marks model highlights body dissatisfaction as an important element in the relationship between emotional functioning and eating behaviours in obese populations. Body dissatisfaction may thus influence eating style and emotional functioning [8]. These theoretical assumptions should be empirically verified. Aside from using mindful eating techniques in an intervention for overweight or obese individuals, it is also important to include other techniques that can reduce emotion dysregulation and negative affect.

The findings regarding uncontrolled eating are not consistent with the literature about mindful eating. Moreover, results regarding the moderation effect of mindful eating in the relationship between emotional eating led to a paradox, where mindful eating seems to exacerbate the negative affects of independent variables on emotional eating behaviours. Identifying inconsistencies and paradoxical effects could be important in research, because discrepant findings could help researchers to update knowledge about a research topic, for example, through identifying new variables that could explain previous inconsistencies.

Briefly, consistent with the theoretical model of obesity described by Hemmingsson [6], Marks [homeostatic theory of obesity; 8] and Raman [clinical obesity maintenance model; 9], the treatment of overweight and obese people should entail techniques focused on the development of mindful eating skills aimed at improvement of emotional functioning. Furthermore, the current results [21, 71, 72] demonstrate that dialectical behaviour therapy (focusing, among others, on emotional functioning) increases the levels of intuitive eating and adaptive emotion regulation while decreasing the levels of binge eating disorder symptoms, emotional eating and psychological distress, and with Wnuk's and Du's [25] model, which describes that mindful eating techniques improve emotional functioning (acceptance and tolerance emotions). Moreover, other studies show 
that mindfulness and mindful eating are associated with food intake (significant and negative relationship with fat and sugar consumption) [73] and mindfulness and emotion regulation abilities can be useful in bariatric surgery candidate [70]. According to what described above, we created a complex psychological intervention (focusing on regulations of emotions, mindful eating and body image) whose effectiveness is currently being evaluated in overweight patients.

To address some of the limitations of the current study, the sample size should be increased, and men should be included as well. Moreover, further research is needed to better investigate the relationship between emotional functioning and uncontrolled eating. Moreover, subsequent studies analysing the relationship between these variables should be longitudinal or experimental. Another limitation is using BMI as an outcome measure of body composition. Subsequent research should use more objective measurements of body composition such as electrical bioimpedance to determine the proportion of body fat relative to lean tissue. In addition, important results may be derived from studies comparing participants with and without mental health disorders. The use of self-reported measures may be a further limitation.

Finally, since effect size was small in all models (interpretation based on $R^{2}$-chng like squared semipartial correlation coefficient: 0.02-small effect, 0.15-medium effect, and 0.35-large effect), the current results should be treated with caution and further supported by research in this field.

\section{Conclusion}

Our findings highlight the importance of mindful eating in the context of restrictive eating in the treatment of overweight and obese people. Aside from using mindful eating techniques in an intervention for overweight or obese individuals, it is also important to include other techniques that can reduce emotion dysregulation and negative affect.

Funding This research was supported by a grant from the SWPS University of Social Sciences and Humanities, Wrocław Faculty of Psychology, Poland (BST/Wroc/2017/B/05).

\section{Compliance with ethical standards}

Conflict of interest The authors declare that they have no conflict of interest.

Ethical approval The research was approved by the local ethics committee (SWPS University of Social Sciences and Humanities, Wrocław Faculty of Psychology, No. 01/E/10/2017). All procedures performed in this study were in accordance with the ethical standards of the institutional and/or national research committee and with the 1964 Helsinki Declaration and its later amendments or comparable ethical stand- ards. Informed consent was obtained from all individual participants included in the study.

Informed consent Informed consent was obtained from all individual participants included in the study.

Open Access This article is distributed under the terms of the Creative Commons Attribution 4.0 International License (http://creativeco mmons.org/licenses/by/4.0/), which permits unrestricted use, distribution, and reproduction in any medium, provided you give appropriate credit to the original author(s) and the source, provide a link to the Creative Commons license, and indicate if changes were made.

\section{References}

1. Arroyo-Johnson C, Mincey KD (2016) Obesity epidemiology worldwide. Gastroenterol Clin N 45(4):571-579. https://doi. org/10.1016/j.gtc.2016.07.012

2. NCD Risk Factor Collaboration (2016) Trends in adult bodymass index in 200 countries from 1975 to 2014: a pooled analysis of 1698 population-based measurement studies with 19.2 million participants. Lancet 387(10026):1377-1396. https://doi. org/10.1016/S0140-6736(16)30054-X

3. World Health Organization (2014) Overweight and obesity. 2014. http://www.who.int/gho/ncd/risk_factors/overweight/en/. Accessed 10 Feb 2018

4. Forster M, Veerman JL, Barendregt JJ, Vos T (2011) Cost-effectiveness of diet and exercise interventions to reduce overweight and obesity. Int J Obes 35:1071-1078. https://doi.org/10.1038/ ijo. 2010.246

5. Hayward J, Jacka FN, Waters E, Allender S (2014) Lessons from obesity prevention for the prevention of mental disorders: the primordial prevention approach. BMC Psychiatry 14:254. https://doi. org/10.1186/s12888-014-0254-3

6. Hemmingsson E (2014) A new model of the role of psychological and emotional distress in promoting obesity: conceptual review with implications for treatment and prevention. Obes Rev 15(9):769-779. https://doi.org/10.1111/obr.12197

7. Lin HY, Huang CK, Tai CM, Lin HY, Kao YH, Tsai CC, Hsuan CF, Lee SL, Chi SC, Yen YC (2013) Psychiatric disorders of patients seeking obesity treatment. BMC Psychiatry 13:1. https ://doi.org/10.1186/1471-244X-13-1

8. Marks DF (2015) Homeostatic theory of obesity. Health Psychol Open 2(1):1-30. https://doi.org/10.1177/2055102915590692

9. Raman J, Smith E, Hay P (2013) The clinical obesity maintenance model: an integration of psychological constructs including mood, emotional regulation, disordered overeating, habitual cluster behaviours, health literacy and cognitive function. Int $\mathbf{J}$ Obes. https://doi.org/10.1155/2013/240128

10. Wiltink J, Michal M, Wild PS, Zwiener I, Blettner M, Münzel T, Schulz A, Kirschner Y, Beutel ME (2013) Associations between depression and different measures of obesity (BMI, WC, WHtR, WHR). BMC Psychiatry 13:223. https://doi. org/10.1186/1471-244X-13-223

11. Micanti F, Iasevoli F, Cucciniello C, Costabile R, Loiarro G, Pecoraro G, Pasanisi F, Rossetti G, Galletta D (2017) The relationship between emotional regulation and eating behaviour: a multidimensional analysis of obesity psychopathology. Eat Weight Disord 22(1):105-115. https://doi.org/10.1007/s40519-016-0275-7

12. Rommel D, Nandrino JL, Ducro C, Andrieux S, Delecourt F, Antoine P (2012) Impact of emotional awareness and parental 
bonding on emotional eating in obese women. Appetite 59(1):2126. https://doi.org/10.1016/j.appet.2012.03.006

13. Rossy L (2016) The mindfulness-based eating solution: proven strategies to end overeating, satisfy your hunger, and savor your life. New Harbinger Publications, Oakland

14. Anglé S, Engblom J, Eriksson T, Kautiainen S, Saha MT, Lindfors P, Lehtinen M, Rimpelä A (2009) Three Factor Eating Questionnaire-R18 as a measure of cognitive restraint, uncontrolled eating and emotional eating in a sample of young Finnish females. Int J Behav Nutr Phys Act 6:41. https://doi. org/10.1186/1479-5868-6-41

15. Brytek-Matera A, Rogoza R, Czepczor-Bernat K (2017) The Three-Factor Eating Questionnaire-R18: an analysis of the factor structure of the Polish version among normal weight and obese adult women. Arch Psychiatr Psychother 3:81-90. https://doi. org/10.12740/APP/76342

16. Czepczor K, Brytek-Matera A (2017) Jedzenie pod wpływem emocji [Emotional eating]. Difin, Warszawa

17. Gratz KL, Roemer L (2004) Multidimensional assessment of emotion regulation and dysregulation: development, factor structure, and initial validation of the difficulties in Emotion Regulation Scale. J Psychopathol Behav 26:41-54

18. Leahy RL, Tirch D, Napolitano L (2014) Regulacja emocji w psychoterapii [emotional regulation in psychotherapy]. Podręcznik praktyka. Wydawnictwo Uniwersytetu Jagiellońskiego, Kraków

19. Pedersen SH, Poulsen S, Lynn S (2014) Affect regulation: holding, containing and mirroring. Int J Psychoanal 95(5):843-864. https ://doi.org/10.1111/1745-8315.12205

20. Silberstein LR, Tirch D, Leahy RL, McGinn L (2012) Mindfulness, psychological flexibility and emotional schemas. Int J Cogn Ther 5:406-419. https://doi.org/10.1521/ijct.2012.5.4.406

21. Cancian ACM, de Souza LAS, Liboni RPA, Machado WL, Oliveira MDS (2017) Effects of a dialectical behavior therapybased skills group intervention for obese individuals: a Brazilian pilot study. Eat Weight Disord. https://doi.org/10.1007/s4051 9-017-0461-2

22. Leehr EJ, Krohmer K, Schag K, Dresler T, Zipfel S, Giel KE (2015) Emotion regulation model in binge eating disorder and obesity: a systematic review. Neurosci Biobehav Rev 49:125-134. https://doi.org/10.1016/j.neubiorev.2014.12.008

23. Zeeck A, Stelzer N, Linster HW, Joos A, Hartmann A (2011) Emotion and eating in binge eating disorder and obesity. Eur Eat Disord Rev 19(5):426-437. https://doi.org/10.1002/erv.1066

24. Conceição EM, Utzinger M, Pisetsky JE (2015) Eating disorders and problematic eating behaviours before and after bariatric surgery: characterization, assessment and association with treatment outcomes. Eur Eat Disord Rev 23(6):417-425. https://doi. org/10.1002/erv.2397

25. Wnuk SM, Du ChT (2017) Mindful eating for severe obesity. In: Sockalingam S, Hawa R (eds) Psychiatric care in severe obesity. Springer, Cham, pp 231-244. https://doi.org/10.1007/978-3-31942536-8_17

26. Alberts HJ, Thwissen R, Raes L (2012) Dealing with problematic eating behaviour. The effects of a mindfulness-based intervention on eating behaviour, food cravings, dichotomous thinking and body image concern. Appetite 58(3):847-851. https://doi. org/10.1016/j.appet.2012.01.009

27. Stellpflug C (2010) Emotional eating "The battle for the mind"! http://www.k12academics.com/articles/emotional-eatin g-\%E2\%80\%9C-battle-mind-\%E2\%80\%9D\#.VuBIhZzhDIU. Accessed 18 Feb 2018

28. van Strien T, Ouwens MA, Engel C, de Weerth C (2014) Hunger, inhibitory control and distress-induced emotional eating. Appetite 79:124-133. https://doi.org/10.1016/j.appet.2014.04.020
29. van Strien T, Herman CP, Verheijden MW (2012) Eating style, overeating and weight gain. A prospective 2-year follow-up study in a representative Dutch sample. Appetite 59:782-789. https:// doi.org/10.1016/j.appet.2012.08.009

30. van Strien T, Herman CP, Verheijden MW (2009) Eating style, overeating, and overweight in a representative Dutch sample. Does external eating play a role? Appetite 52(2):380-387. https ://doi.org/10.1016/j.appet.2008.11.010

31. Orcutt M, Steffen K, Mitchell JE (2017) Eating disorders and problematic eating behaviors after bariatric surgery. In: Agras WS, Robinson A (eds) The oxford handbook of eating disorders, 2nd edn. Oxford, New York. https://doi.org/10.1093/oxfordhb/97801 90620998.013.25

32. Jacobs J, Cardaciotto L, Block-Lerner J, McMahon C (2013) A pilot study of a single session training to promote mindful eating. Mind Body Med 27(2):18-23

33. Kristeller JL, Wolever RQ, Sheets V (2013) Mindfulness-based eating awareness training (MB-EAT) for binge eating disorder: a randomized clinical trial. Mindfulness 3(4):261-338. https://doi. org/10.1007/s12671-012-0179-1

34. Smart R, Chisum A, Robertson-Pfeffer K, Tsong Y (2015) Women's experience with a mindful eating course on a university campus: a pilot study. Calif J Health Promot 13(1):59-65

35. Wnuk SM, Du ChT, Van Exan J, Wallwork A, Warwick K, Tremblay L, Kowgier M, Sockalingam S (2017) Mindfulness-based eating and awareness training for post-bariatric surgery patients: a feasibility pilot study. Mindfulness. https://doi.org/10.1007/s1267 1-017-0834-7

36. Kristeller JL, Wolever RQ (2011) Mindfulness-based eating awareness training for treating binge eating disorder: the conceptual foundation. Eat Disord 19(1):49-61. https://doi. org/10.1080/10640266.2011.533605

37. Meier BP, Noll SW, Molokwu OJ (2017) The sweet life: the effect of mindful chocolate consumption on mood. Appetite 108:21-27. https://doi.org/10.1016/j.appet.2016.09.018

38. Beshara M, Hutchinson AD, Wilson C (2013) Does mindfulness matter? Everyday mindfulness, mindful eating and self-reported serving size of energy dense foods among a sample of South Australian adults. Appetite 67:25-29. https://doi.org/10.1016/j.appet .2013.03.012

39. Lattimore P, Fisher N, Malinowski P (2011) A cross-sectional investigation of trait disinhibition and its association with mindfulness and impulsivity. Appetite 56(2):241-248. https://doi. org/10.1016/j.appet.2010.12.007

40. Pidgeon A, Lacota K, Champion J (2013) The moderating effects of mindfulness on psychological distress and emotional eating behaviour. Aust Psychol 48(4):262-269. https://doi.org/10.111 1/j.1742-9544.2012.00091.x

41. Allirot X, Miragall M, Perdices I, Baños RM, Urdaneta E, Cebolla A (2017) Effects of a brief mindful eating induction on food choices and energy intake: external eating and mindfulness state as moderators. Mindfulness. https://doi.org/10.1007/s1267 1-017-0812-0

42. Jordan CH, Wang W, Donatoni L, Meier BP (2014) Mindful eating: trait and state mindfulness predict healthier eating behavior. Pers Individ Differ 68:107-111. https://doi.org/10.1016/j. paid.2014.04.013

43. Hruby A, Hu FB (2015) The epidemiology of obesity: a big picture. Pharmacoeconomics 33(7):673-689. https://doi.org/10.1007/ s40273-014-0243-x

44. Hopkins LB, Medina JL, Baird SO, Rosenfield D, Powers MB, Smits JA (2016) Heated hatha yoga to target cortisol reactivity to stress and affective eating in women at risk for obesity-related illnesses: a randomized controlled trial. J Consult Clin Psychol 84(6):558-564. https://doi.org/10.1037/ccp0000091 
45. O’Reilly GA, Cook L, Spruijt-Metz D, Black DS (2014) Mindfulness-based interventions for obesity-related eating behaviors: a literature review. Obes Rev 15(6):453-461. https://doi.org/10.1111/ obr.12156

46. Lofgren IE (2015) Mindful eating: an emerging approach for healthy weight management. Am J Lifestyle Med 9(3):212-216. https://doi.org/10.1177/1559827615569684

47. Carrière K, Khoury B, Günak MM, Knäuper B (2018) Mindfulness-based interventions for weight loss: a systematic review and meta-analysis. Obes Rev 19(2):164-177. https://doi.org/10.1111/ obr. 12623

48. Rogers JM, Ferrari M, Mosely K, Lang CP, Brennan L (2017) Mindfulness-based interventions for adults who are overweight or obese: a meta-analysis of physical and psychological health outcomes. Obes Rev 18(1):51-67. https://doi.org/10.1111/obr.12461

49. Ruffault A, Czernichow S, Hagger MS, Ferrand M, Erichot N, Carette C, Boujut E, Flahault C (2016) The effects of mindfulness training on weight-loss and health-related behaviours in adults with overweight and obesity: a systematic review and metaanalysis. Obes Res Clin Pract 11(5 Suppl 1):90-111. https://doi. org/10.1016/j.orcp.2016.09.002

50. Olson KL, Emery CF (2015) Mindfulness and weight loss: a systematic review. Psychosom Med 77(1):59-67. https://doi. org/10.1097/PSY.0000000000000127

51. Katterman SN, Kleinman BM, Hood MM, Nackers LM, Corsica JA (2014) Mindfulness meditation as an intervention for binge eating, emotional eating, and weight loss: a systematic review. Eat Behav 15(2):197-204. https://doi.org/10.1016/j.eatbe h.2014.01.005

52. Godsey (2013) The role of mindfulness based interventions in the treatment of obesity and eating disorders: an integrative review. Complement Ther Med 21(4):430-439. https://doi.org/10.1016/j. ctim.2013.06.003

53. American Psychiatric Association (2000) DSM-IV-TR: diagnostic and statistical manual of mental disorders. American Psychiatric Publishing, Arlington

54. Bédard A, Hudon AM, Drapeau V, Corneau L, Dodin S, Lemieux $S$ (2015) Gender differences in the appetite response to a satiating diet. J Obes. https://doi.org/10.1155/2015/140139

55. da Luz FQ, Hay P, Touyz S, Sainsbury A (2018) Obesity with comorbid eating disorders: associated health risks and treatment approaches. Nutrients 10(7):E829. https://doi.org/10.3390/nu100 70829

56. Watson D, Clark LA, Tellegen A (1998) Development and validation of brief measures of positive and negative affect: the PANAS scales. J Pers Soc Psychol 54(6):1063-1070

57. Karlsson J, Persson L-O, Sjöström L, Sullivan M (2000) Psychometric properties and factor structure of the Three-Factor Eating Questionnaire (TFEQ) in obese men and women. Results from the Swedish obese subjects (SOS) study. Int J Obes 24(12):17151725. https://doi.org/10.1038/sj.ijo.0801442

58. Hulbert-Williams L, Nicholls W, Joy J, Hulbert-Williams N (2014) Initial validation of the Mindful Eating Scale. Mindfulness 5(6):719-729. https://doi.org/10.1007/s12671-013-0227-5

59. Perez J, Venta A, Garnaat S, Sharp C (2012) The Difficulties in Emotion Regulation Scale: factor structure and association with nonsuicidal self-injury in adolescent inpatients. J Psychopathol Behav Assess 34:393. https://doi.org/10.1007/s10862-012-9292-7

60. Norlander T, Bood SA, Archer T (2002) Performance during stress: affective personality, age, and regularity of physical exercise. Soc Behav Pers 30:495-508. https://doi.org/10.2224/ sbp.2002.30.5.495

61. Brzozowski P (2010) Skala uczuć pozytywnych i negatywnych SUPIN [positive and negative affect schedule SUPIN]. Pracownia Testów Psychologicznych Polskiego Towarzystwa Psychologicznego, Warszawa

62. Hayes AF (2018) Introduction to mediation, moderation, and conditional process analysis: a regression-based approach, 2 nd edn. The Guilford Press, New York

63. Fisher N, Lattimore P, Malinowski P (2016) Attention with a mindful attitude attenuates subjective appetitive reactions and food intake following food-cue exposure. Appetite 99:10-16. https ://doi.org/10.1016/j.appet.2015.12.009

64. Haynos AF, Wang SB, Fruzzetti AE (2018) Restrictive eating is associated with emotion regulation difficulties in a non-clinical sample. Eat Disord 26:5-12. https://doi.org/10.1080/10640 266.2018.1418264

65. Racine SE, Horvath SA (2018) Emotion dysregulation across the spectrum of pathological eating: comparisons among women with binge eating, overeating, and loss of control eating. Eat Disord 26:13-25. https://doi.org/10.1080/10640266.2018.1418381

66. Mason TB, Lewis RJ (2014) Profiles of binge eating: the interaction of depressive symptoms, eating styles, and body mass index. Eat Disord 22(5):450-460. https://doi.org/10.1080/10640 266.2014.931766

67. Bays JC (2009) Mindful eating: a guide to rediscovering a healthy and joyful relationship with food. Shambhala, Boston

68. Kristeller JL (2016) The struggle continues: addressing concerns about eating and weight for older women's well-being. Women Ther 39(1-2):202-212. https://doi.org/10.1080/02703 149.2016.1116855

69. Kristeller JL, Lieberstein AE (2016) Teaching individuals mindful eating. In: McCown D, Reibel D, Micozzi M (eds) Resources for teaching mindfulness. Springer, Cham, pp 359-378. https://doi. org/10.1007/978-3-319-30100-6_19

70. Dalrymple KL, Clark H, Chelminski I, Zimmerman M (2018) The interaction between mindfulness, emotion regulation, and social anxiety and its association with emotional eating in bariatric surgery candidates. Mindfulness 9:1780-1793. https://doi. org/10.1007/s12671-018-0921-4

71. Beaulac J, Sandre D, Mercer D (2018) Impact on mindfulness, emotion regulation, and emotional overeating of a dbt skills training group: a pilot study. Eat Weight Disord. https://doi. org/10.1007/s40519-018-0616-9

72. Kamody RC, Thurston IB, Pluhar EI, Han JC, Burton ET (2018) Implementing a condensed dialectical behavior therapy skills group for binge-eating behaviors in adolescents. Eat Weight Disord. https://doi.org/10.1007/s40519-018-0580-4

73. Mantzios M, Egan H, Hussain M, Keyte R, Bahia H (2018) Mindfulness, self-compassion, and mindful eating in relation to fat and sugar consumption: an exploratory investigation. Eat Weight Disord. https://doi.org/10.1007/s40519-018-0548-4

Publisher's Note Springer Nature remains neutral with regard to jurisdictional claims in published maps and institutional affiliations. 